
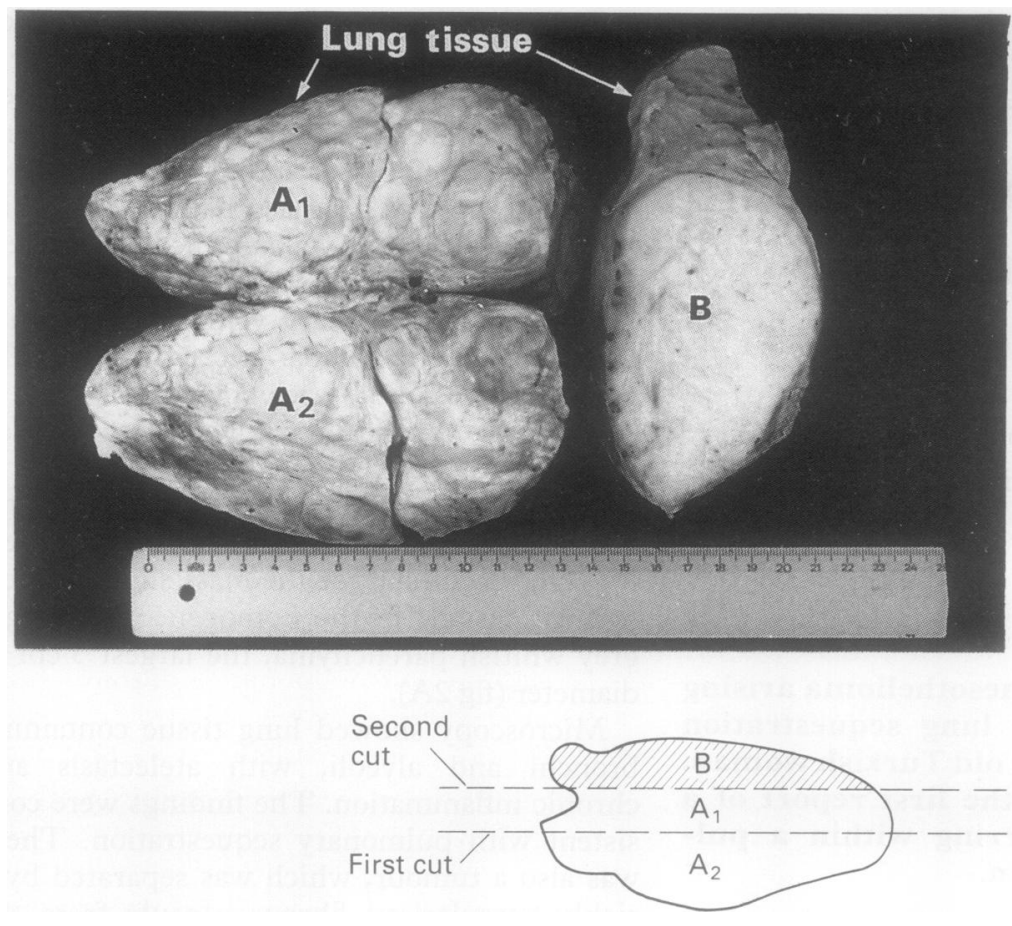

1 Savic B, Birtel FJ, Tholen W, Funke HD, Knoche R. Lung sequestration: report of seven cases and review of 540 published cases. Thorax 1979;34:96-101.

2 Carter R. Pulmonary sequestration. Ann Thorac Surg 1969; 7:68-88.

3 Stocker JT, Kagan-Hallet K. Extralobar pulmonary sequestration. Analysis of 15 cases. Am J Clin Pathol 1931;11: 385-412.

4 Scharifkar D, Kaneko M. Localised fibrous "mesothelioma"

\title{
Corynebacterium pseudodiphtheriticum pneumonitis in a leukaemic child
}

\section{Department of \\ Pathology \\ N Cimolai \\ P Rogers \\ Department of \\ Pediatrics \\ P Rogers \\ M Seear}

University of British

Columbia, Vancouver

Program of

Microbiology,

Department of

Pathology, British

Columbia's Children's

Hospital, Vancouver,

British Columbia,

Canada V6H 3V4

N Cimolai

Reprint requests to:

Dr N Cimolai

Accepted 13 November 1991
N Cimolai, P Rogers, M Seear

\section{Abstract \\ A 6 year old boy receiving chemotherapy for acute lymphocytic leukaemia developed pneumonia due to Coryne- bacterium pseudodiphtheriticum. He responded to antibiotics.}

(Thorax 1992;47:838-839)

Among the pathogenic non-diphtheria corynebacteria, Corynebacterium pseudodiphtheriticum is reported to cause human infection uncommonly despite its presence in the common flora of the upper respiratory tract. ${ }^{12} \mathrm{We}$ describe the first child recognised to have had lower respiratory infection with this bacterium.

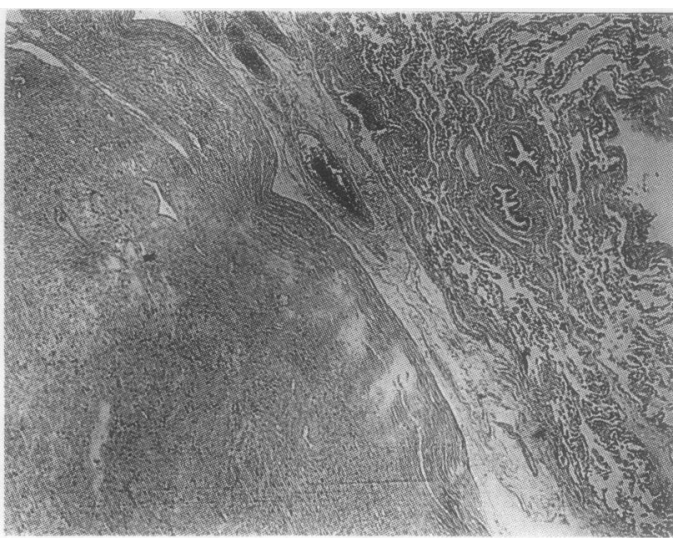

Figure 2 (A) Gross pathological appearance of the nodular, vascular tumour and its attachment to the lung, with a diagram of the cut surfaces. The two pieces on the left show the cut surfaces of the mass, which was cut horizontally from the midline $\left(A_{1}, A_{2}\right)$. The piece on the right shows the cut surface of the nodular projection on top of the mass $(B)$. The darker area on top of piece $B$ is the lung tissue. (B) Photomicrograph showing an area of the tumour that was separated from the adjacent lung parenchyma by a vascular fibrous capsule. (Haematoxylin and eosin.)

of pleuro (submesothelial fibroma). A clinicopathological study of 18 cases. Cancer 1979;43:627-35.

5 Dalton WT, Zolliker AS, McCaughey WTE, Jacques J, Kannerstein M. Localised primary tumours of the pleura. An analysis of 40 cases. Cancer 1979;44:1465-75.

6 Said JW, Nash G, Banks-Schlegel S, Sassoon A, Shintaku IP. Localised fibrous mesothelioma: an immunohistochemical and electron microscopic study. Hum Pathol 1984;15:440-3.
Case report

A 6 year old boy was admitted to hospital with subacute pneumonia. He had been diagnosed as having acute lymphocytic leukaemia 30 months before and had received chemotherapy until admission. A persistent dry cough had developed six months before this admission, which seemed to improve with salbutamol. Pulmonary infiltrates had not been seen radiologically two months previously. Right middle and lower lobe infiltrates appeared one month before admission and the patient became febrile one week before. On admission he had tachypnoea (36/min) and tachycardia ( 116 beats/ $\mathrm{min}$ ) and adventitious sounds were heard at both lung bases. A central venous line was in place. The initial white blood cell count was $6.8 \times 10^{9} / 1$, with only $11 \%$ lymphocytic forms; the haemoglobin concentration was $7 \cdot 8 \mathrm{~g} / \mathrm{dl}$. Quantitative immunoglobulin studies showed a low IgG concentration $(5.62 \mathrm{~g} / 1)$ but normal $\operatorname{IgM}$ and $\operatorname{IgA}$. He had selective $\operatorname{IgG}_{2}$ deficiency $(0.31 \mathrm{~g} / 1)$ but values for $\mathrm{IgG}_{1}, \mathrm{IgG}_{3}$, and $\mathrm{IgG}_{4}$ were normal. At bronchoscopy purulent secretions were seen, which contained many polymorphonuclear cells and many cell associated diphtheroid Gram positive bacilli. Vancomycin and erythromycin were started. The washings yielded a heavy growth of $C$ 
pseudodiphtheriticum with a light to moderate mixed growth of common oral bacteria. The corynebacterium was susceptible to penicillin, all cephalosporins, aminoglycosides, fusidic acid, and vancomycin but resistant to erythromycin, chloramphenicol, and cotrimoxazole. Because of a history of penicillin allergy, cefotaxime was administered for 14 days. The patient became afebrile and improved clinically within a few days. Resolution of the pulmonary infiltrates was documented radiologically. Cultures of bronchoscopy fluid were negative for viruses, fungi, mycobacteria, legionellae, Mycoplasma pneumoniae, Bordetella pertussis, and chlamydiae. Echocardiography did not show evidence of endocarditis. Multiple blood cultures from both central and peripheral venous sites were negative, and urine analysis showed no abnormalities. Twenty days after hospital discharge the patient had only an infrequent cough. Repeat bronchoscopies three and six months later showed that purulent secretions were present with a predominance of neutrophils, but the corynebacterium was not cultured.

\section{Discussion}

This report represents the first description of pulmonary disease caused by $C$ pseudodiphtheriticum in a child, though a few adults with pulmonary infections have been reported. ${ }^{3-8}$ Although several of the patients were apparently immunocompetent, all had been debilitated by either an underlying chronic disease or preceding pulmonary damage. This may explain the paucity of infections in children. The descriptions of pulmonary disease have varied and have included unilateral and bilateral infiltrates, cavitation, and tracheitis. Two of the 12 patients died but both were elderly men with preceding chronic lung disease. Our patient had depressed total IgG and $\mathrm{IgG}_{2}$ concentrations, and preceding pulmonary damage secondary to cytotoxic chemotherapy cannot be excluded; the repeat bronchoscopies suggested the presence of a chronic inflammatory process. Most of the other $C$ pseudodiphtheriticum infections were endocarditides. ${ }^{12}$

The pathological response to infection appears to be a purulent exudate with polymorphonuclear cells. Exotoxin production analogous to that of $C$ diphtheriae is not recognised. Despite immunosuppression or lung damage the host is usually able to contain the microorganism, as shown by the absence of bacteraemia in the previous cases reported. Gram stains of respiratory secretions are of value in showing Gram positive diphtheroid bacilli in the presence of polymorphonuclear cells. This finding should prompt the laboratory to search for corynebacteria diligently. The bacterial burden in bronchoscopy specimens from our patient was not apparent from the cultures at 24 hours owing to the small size of the colonies. By 48-72 hours, however, a heavy growth of bacteria that substantially outnumbered the usual growth from contaminating oral flora was apparent. Had not the Gram stain been so remarkable, possibly $C$ pseudodiphtheriticum would have been considered simply a normal part of the oral flora contaminants.

Several other Corynebacterium species have been associated with pulmonary infection, usually in immunocompromised patients. ${ }^{2}$ Because of the resistance profile of some (for example, $C$ jeikeium), initial treatment with vancomycin is recommended for serious infections. Pulmonary infections with $C$ pseudodiphtheriticum appear to be subacute. We believe that infection and pulmonary infiltrates were developing over several weeks before the acute deterioration in our patient. It is uncertain whether the two recorded deaths after $C$ pseudodiphtheriticum infection were due to the bacterium or to the severe underlying pulmonary disease. Treatment of $C$ pseudodiphtheriticum pulmonary infection with $\beta$ lactam agents or norfloxacin has been associated with good outcomes, and these outcomes have been associated with in vitro drug susceptibility..$^{3-8}$ In one patient, treated with fosfomycin for a different purpose, in vitro resistance was associated with lack of response clinically and bacteriologically. Published antibiograms note the variable sensitivity to erythromycin, clindamycin, and chloramphenicol. Further experience with this microorganism will help to define appropriate antibiotics.

We thank Heidi Luking, Colleen Trombley, and Michelle Graham for their assistance.

1 Lipsky BA, Goldberger AC, Tompkins LS, Plorde JJ. Infections caused by nondiphtheria corynebacteria. $R e v$ Infect Dis 1982;4:1220-35.

2 Coyle MB, Lipsky B. Coryneform bacteria in infectious diseases: clinical and laboratory aspects. Clin Microbiol Rev 1991;3:227-46.

3 Donaghy M, Cohen J. Pulmonary infection with Corynebacterium hofmanii complicating systemic lupus erythematous. J Infect Dis 1983;147:962.

4 Miller RA, Rompalo A, Coyle MB. Corynebacterium pseudodiphtheriticum pneumonia in an immunologically intact host. Diagn Microbiol Infect Dis 1986;4:165-71.

5 Andavolu RH, Jagadha V, Lue Y, McLean T. Lung abscess involving Corynebacterium pseudodiphtheriticum in a patient with AIDS-related complex. NY State J Med 1986;36:594-6.

6 Rikitomi, N, Nagatake T, Matsumoto K, Watanabe K, Mbaki N. Lower respiratory tract infections due to nondiphtheria corynebacteria in 8 patients with underlying lung diseases. Tohoku Journal of Experimental Medicine 1987;153:313-25.

7 Douat N, Labbe M, Glupczynski G. Corynebacterium pseudodiphtheriticum pneumonia in an arthracosilicotic man. Clinical Microbiology Newsletter 1989;11:189-90.

8 Colt HG, Morris JF, Marston BJ, Sewell DL. Nectrotizing tracheitis caused by Corynebacterium pseudodiphtheriticum: unique case and review. Rev Infect Dis 1991;13: 73-6. 